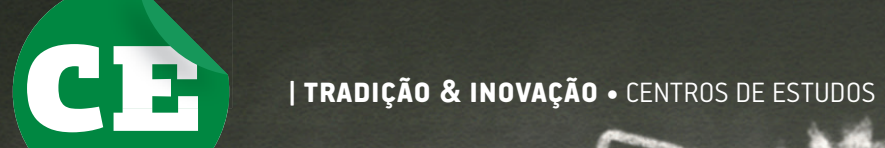

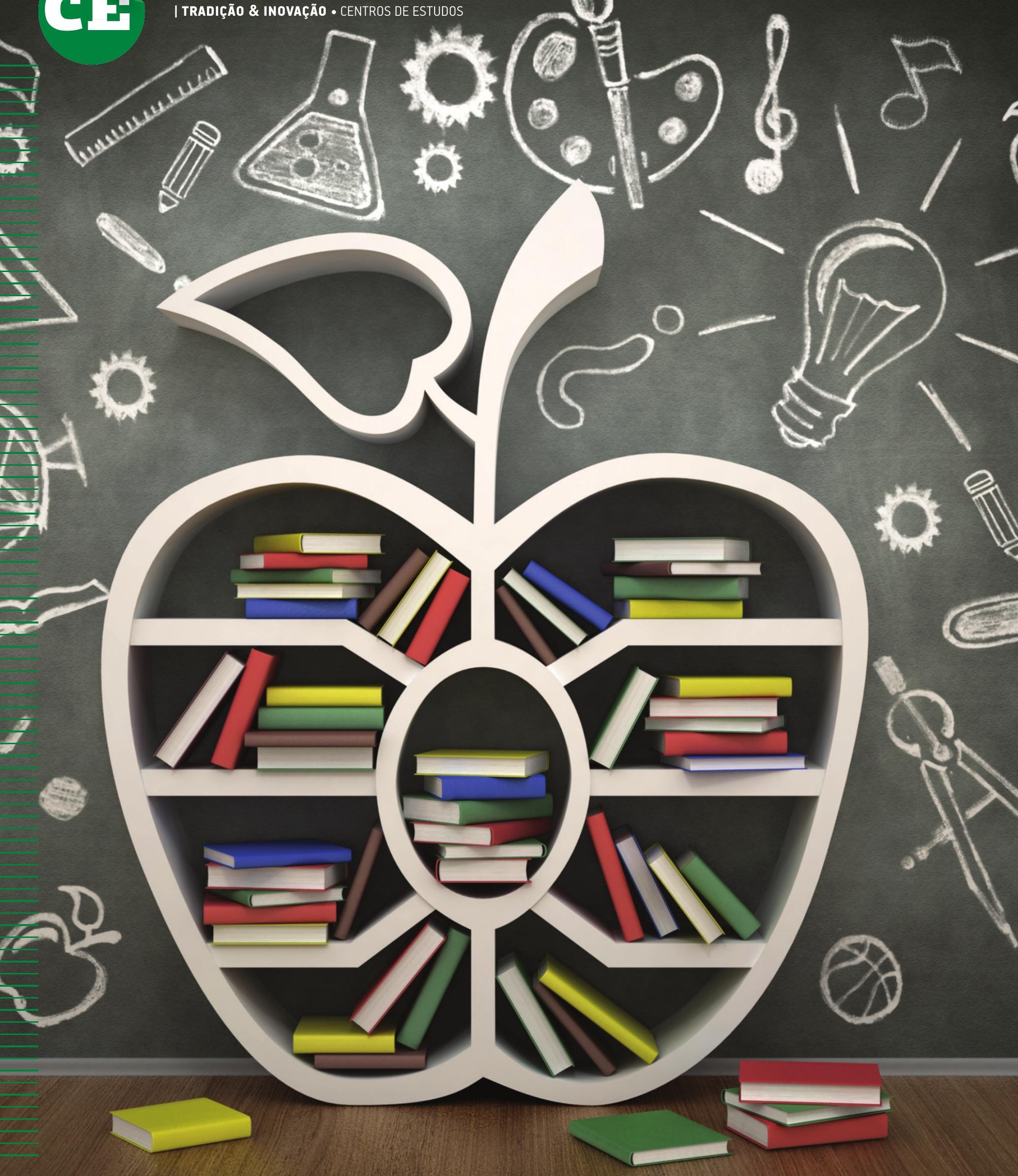




\section{CENTROS DE ESTUDOS: ESPAÇOS DE PROPAGAÇÃO DO SABER}

\section{SAIBA MAIS SOBRE CENTROS DE ESTUDOS DA EAESP, ESPAÇOS DE CRIAÇÃO, COMPARTILHAMENTO E DISSEMINAÇÃO DE CONHECIMENTO ENTRE PROFESSORES, ALUNOS, EMPRESAS E COMUNIDADE}

\section{| POR ROSANA CÓRDOVA}

\section{COMO TUDO COMEÇOU}

Era dezembro de 1989, momento em que o Brasil já vivia um processo de abertura democrática com o fim do período militar, a eleição direta de Tancredo Neves e também com a promulgação da nova Constituição Federal em 1988, que mudaria substancialmente a realidade brasileira nos últimos 20 anos. A FGVEAESP observava e acompanhava as mudanças na sociedade e desejava contribuir mais com aquele momento.

$\mathrm{Na}$ época, já existia na área de saúde o Programa de Estudos Avançados em Administração Hospitalar e Sistemas de Saúde (PROAHSA), apoiado pela Fundação Kellogg e com convênio de cooperação com a FGV-EAESP, o Hospital das Clínicas de São Paulo e a Faculdade de Medicina da Universidade de São Paulo. O objetivo do PROAHSA era a formação de equipes e estudos na área de gestão de saúde e pode ser considerada a ideia inicial do que viriam a ser os Centros de Estudos.

De acordo com Peter Spink, professor da FGV-EAESP, "havia um déficit imenso de serviços públicos, uma falta de preparação de pessoas para a área pública. A Escola tinha um curso de Administração Pública que era uma espécie de 'sombra' do curso de Administração de Empresas". As circunstâncias, portanto, favoreceram a criação de uma Comissão de Administração Pública pelo então presidente da FGV-EAESP, professor Marcos Cintra, para avaliar o Programa de Pósgraduação em Administração Pública e as diretrizes de reformulação da área. O resultado inicial do relatório produzido por essa comissão foi a proposta e posterior abertura do Mestrado Acadêmico na área de Administração Pública. A criação desse curso foi o estímulo necessário para que surgisse, em seguida, o primeiro Centro de Estudos da FGV-EAESP, o Centro de Estudos de Administração Pública e Governo (CEAPG), que, neste ano, completará 25 anos em plena atividade.

\section{EXPANSÃO DOS CENTROS}

Com a criação do CEAPG, outros Centros também foram aparecendo e, de 1990 até por volta de 2005, os professores foram incentivados a desenvolver Centros de Estudos dentro da FGV-EAESP. Para a Escola, era interessante que professores e alunos convivessem mais, ocupassem salas e dependências. Os Centros foram muito importantes para trazer as pessoas para dentro da FGV-EAESP e possibilitar para que não houvesse somente salas de aula e salas dos professores, mas também um espaço de trocas. Para o professor Spink, "os Centros viraram um atributo da Escola, algo que cruza professor, professor visitante, alunos de pós e alunos de graduação".

Nesse período de 15 anos, os critérios para a abertura dos Centros de Estudos ainda não estavam delimitados. Foi um período de experimentação, em que Centros surgiram e alguns se envolveram mais com pesquisa aplicada, outros com cursos e eventos; outros, por sua vez, foram atrás de doações e apoios internacionais etc. Muito conteúdo foi gerado nessa fase, sempre com a regra de que a produção, mesmo que financiada por empresas, deve ser de acesso público e disponível gratuitamente.

\section{FORTALECIMENTO E CRITÉRIOS DE AVALIAÇÃO}

Com a ampliação do número de Centros de Estudo atualmente, são 11 em plena atividade, mas já foram mais 

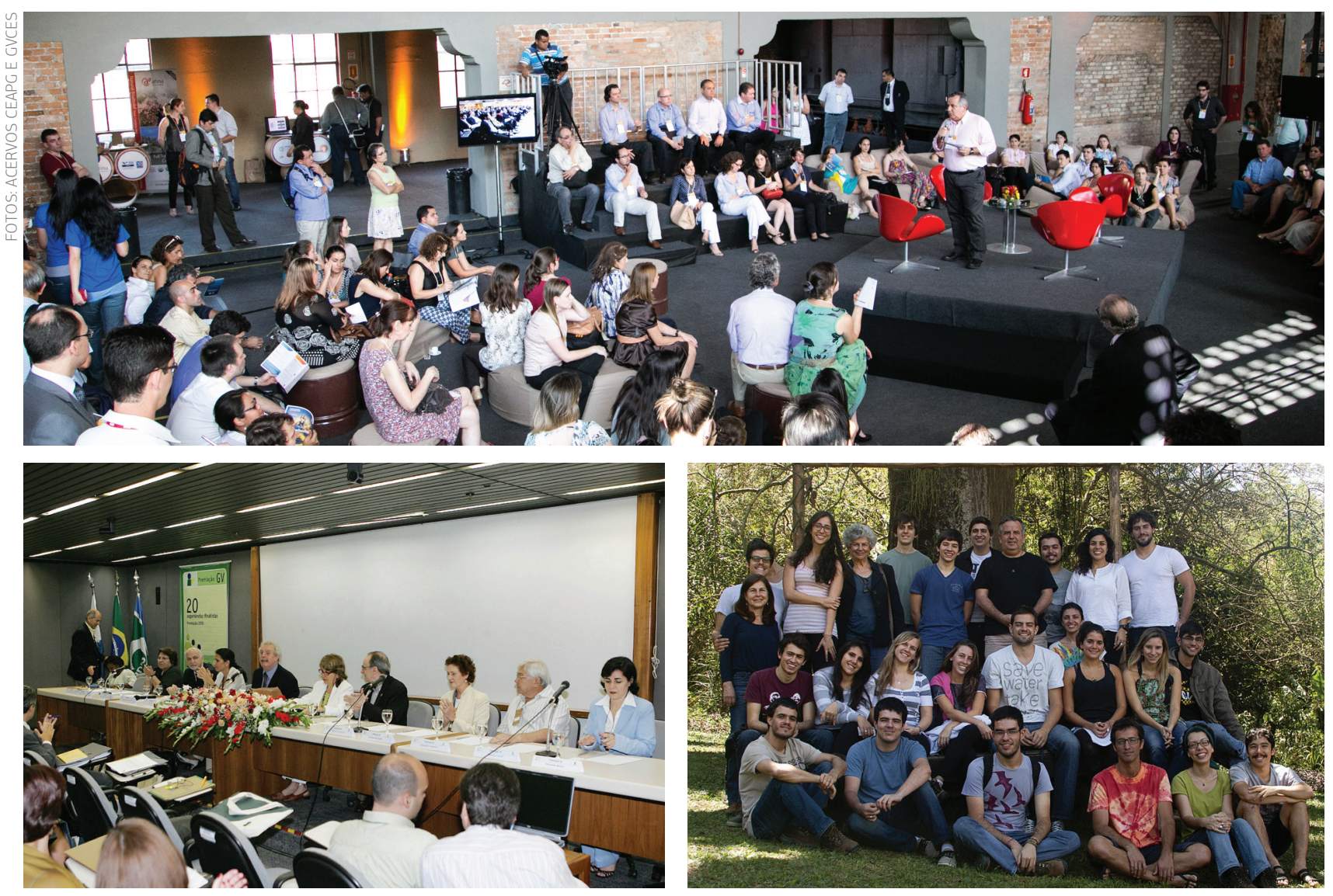

Atividades realizadas pelos Centros de Estudos CEAPG e GVCES

de 20 -, elaboraram-se critérios mais claros de funcionamento: a FGV-EAESP cede o espaço e apoios administrativos, por exemplo, cuida da contabilidade, oferece internet wireless, telefone etc. Em contrapartida, o Centro precisa agrupar pesquisadores, fazer um plano de negócios sobre um tema, delimitando subtemas, o que será produzido etc. Um comitê avalia anualmente o desempenho dos Centros e, em alguns casos, sugere o seu funcionamento no formato mais informal como programa ou núcleo.

Os Centros são bastantes heterogêneos. "Hoje se tem uma grande variedade entre os Centros. Uns fazem pouquíssimos eventos por ano; outros, toda semana, e alguns operam multiprojetos", esclarece o professor Thomaz Wood Jr.

\section{O QUE SE ESPERA PARA O FUTURO}

Para os próximos anos, o quadro é bastante otimista. $\mathrm{O}$ professor Spink, integrante do CEAPG, revela que há projetos que serão realizados fora da Escola, em uma espécie de estação de campo na zona sul de São Paulo. "Trata-se de um estudo sobre vulnerabilidades institucionais. É uma retomada de trabalhos que fizemos nos anos 2000 sobre estratégias locais de redução de pobreza. Tem muitas coisas acontecendo lá e nós temos que nos envolver".

É compromisso dos Centros se conectar com a realidade, captar assuntos importantes, tratar dos temas de um jeito científico e depois devolver para a sociedade. Para o professor Wood Jr., "todos os projetos desse ano têm impacto interessante para empresas e comunidade. Os vídeos mais assistidos no portal da FGV-EAESP são do CELOG, com foco em logística, do Cepesp, que trabalha com o tema da corrupção, e do CEAPG, com investigações sobre gestão pública. São assuntos do momento. A contribuição já é grande e o potencial é gigantesco".

Os Centros de Estudos são uma porta aberta da FGV-EAESP para a sociedade e as empresas. Geram fluxo de conhecimento entre pesquisadores e alunos com empresas, instituições e governo. É um modelo que incentiva o trabalho de pesquisa coletiva, virtuoso, motivador e que capta e dissemina conhecimento para toda a comunidade. 


\section{INSTITUTO DE FINANÇAS: ESPÍRITO COLABORATIVO E MAIOR SINERGIA NOS ESTUDOS FINANCEIROS}

Em maio de 2012, a FGV-EAESP criou o Instituto de Finanças (IFIN), com o propósito de integrar as múltiplas competências desenvolvidas por Centros de Estudos e Núcleos ligados a finanças, além de estimular novas iniciativas de cooperação com outras instituições de pesquisa, promover diálogos entre a academia e os setores público e privado, e divulgar de modo eficaz as ações para a sociedade.

Para o professor João Douat, coordenador do IFIN, "o Instituto é um conceito que está permeando a gestão dos Centros que já existem com a temática de finanças, sem retirar a autonomia que eles já possuem". Desde o início das atividades, alguns núcleos de estudos já foram implantados: Estudos da Felicidade e Comportamento Financeiro; Controladoria e Contabilidade; Finanças Internacionais; Estudos de Risco e Estudos de Value Based Management.
Além dos Núcleos e Centros de Estudos - Estudos em Finanças, Microfinanças e Private Equity -, também está nos planos do IFIN a criação de dois laboratórios, o Laboratório de Gestão Bancária, para analisar questões referentes a juros, spread, rentabilidade de operações e análises de crédito, e o Laboratório de Mercado de Capitais, para realizar simulações utilizando jogos eletrônicos.

Com a função de oferecer maior entrosamento aos envolvidos, atualmente o IFIN conta com a participação de mais de 20 docentes e tem cerca de 30 projetos em andamento. Para o professor Douat, o IFIN surge para facilitar a comunicação, pois quando a ideia é boa e facilmente comunicada, torna-se mais simples obter recursos e patrocínios, promover parcerias e associações e fornecer ao público interessado mais pesquisas acadêmicas e gerenciais

\section{CENTROS DE ESTUDOS DA FGV-EAESP}

\section{Centro de Empreendedorismo e Novos Negócios (GVcenn)}

Centro de Estudos de Política e Economia do Setor Público (Cepesp)

Centro de Estudos em Administração Pública e Governo (CEAPG)

Centro de Estudos em Finanças (GVcef)

\section{Centro de Estudos em} Microfinanças (CEMF)

\section{Centro de Estudos em Planejamento e Gestão de Saúde (GVsaúde)}

\section{Centro de Estudos em Private Equity (GVcepe)}

Centro de Estudos em Sustentabilidade (GVces)

\section{Centro de Excelência em Logística e Supply Chain (GVcelog)}

\section{Centro de Excelência em Varejo (GVcev)}

\section{Centro de Tecnologia de Informação Aplicada (GVcia)}

O GVcenn promove a geração de conhecimento brasileiro sobre empreendedorismo, realizando eventos, workshops, competições sobre planos de negócios, concursos de casos, publicações, cursos, congressos e pesquisas.

As pesquisas do Cepesp privilegiam a relação entre a política e a economia na compreensão das restrições e potencialidades das políticas públicas nos três níveis de governo (Federação, Estados e Municípios).

As áreas de estudos pesquisadas pelo CEAPG incluem: desenvolvimento local, pobreza e desigualdade; difusão e disseminação de inovações e questões de ação pública.

O GVcef produz artigos acadêmicos e rankings (Guia de Fundos da Revista Exame, Guia de Fundos e Guia de Previdência da Revista Você S/A, Guia Valor 1000, entre outros) para revistas, congressos e outras publicações renomadas no Brasil e no exterior.

O CEMF busca promover a reflexão, a análise, a produção do conhecimento, a formulação de estratégias e a proposição de mudanças institucionais para o setor de microfinanças, tendo como eixos norteadores a inclusão financeira e o desenvolvimento local.

O objetivo do GVsaúde é desenvolver projetos de alta qualidade, compartilhados com as unidades da FGV na área de Planejamento e Gestão em Saúde.

O GVcepe é comprometido com o pensamento, a análise, a produção de conhecimento, a educação, e a formulação de propostas de evolução institucional da indústria de Private Equity e Venture Capital no país.

O GVces busca contribuir para a implementação do desenvolvimento sustentável em suas várias dimensões - equidade, justiça social, equilíbrio ecológico e eficiência econômica —, por meio do estudo e da disseminação de conceitos e práticas.

O objetivo do GVcelog é ser no Brasil um referencial em conhecimentos de estratégia e processos de gestão nas áreas de administração logística e supply chain management e estimular e viabilizar a geração, sistematização, difusão e aplicação de conhecimentos sobre estratégia e processos de gestão nessas áreas.

O GVcev busca atuar como catalisador do processo de desenvolvimento e evolução do varejo no Brasil, por meio de atividades nas áreas de educação e formação, pesquisa e consultoria.

O objetivo do GVcia é estimular e coordenar os principais esforços de pesquisa sobre as áreas relacionadas com administração de Tecnologia de Informação, seus cenários e tendências, além de contribuir com outras áreas acadêmicas e administrativas. 